\title{
The Effects of Capsaicin and Vitamine E on High Fat Diet Induced Obesity, Hyperlipidemia and Oxidative Stress in Different Organs of Mice
}

\author{
Birsen Aydin* \\ Amasya University, Faculty of Science, Department of Molecular Biology, Amasya, Turkey \\ *Corresponding author: birsenki@gmail.com
}

Received April 29, 2015; Revised June 08, 2015; Accepted June 12, 2015

\begin{abstract}
Obesity has become a leading global health problem and risk factor for development of a multiple organ dysfunction. The present study was aimed to determine effects of capsaicin (CAP) and Vitamine E (Vit E) on oxidative stress in certain extrahepatic tissue (kidney, heart, lung, intestine, spleen and thymus) and blood lipid levels of high fat (HF) diet mice. Fifty swiss albino mice were segregated into two groups; one fed standard diet (NC) and the other fed high-fat diet (HF) for 12 weeks. After 12 weeks, the HF group was divided into four groups according to whether they received supplements for 4 weeks: the HF group was fed high fat diet only; the HFC group given CAP ( $5 \mathrm{mg} / \mathrm{kg}$, intragasticially); HFE group given Vit E (100 mg/kg, intragasticially) and HFCE group given together CAP and Vit E along with high fat diet. We inferred significant decrease in enzymatic and nonenzymatic antioxidants along with increase in kidney and heart injury markers such as urea, creatine, creatine kinase -MB (CK-MB) lactate dehidrogenase (LDH) and hyperlipidemia in high fat diet fed mice. Capsaicin and Vit E ameliorate these toxicity which might be explained partially via diminishing the generation of free radicals and hyperlipidemia. CAP and Vit E given together has been more effective on decreasing weight, fat pad gain and inflammation than the groups these supplement given separately. On the other hand, combined supplementation of CAP and Vit E showed not better effect on oxidative stress, hyperlipidemia and organ demage markers as compared to treatment alone.
\end{abstract}

Keywords: capsaicin, high fat diet, hyperlipidemia, oxidative stress, $\alpha$-tocopherol

Cite This Article: Birsen Aydin, "The Effects of Capsaicin and Vitamine E on High Fat Diet Induced Obesity, Hyperlipidemia and Oxidative Stress in Different Organs of Mice.” Journal of Food and Nutrition Research, vol. 3, no. 6 (2015): 357-364. doi: 10.12691/jfnr-3-6-1.

\section{Introduction}

High fat diets are responsible for high global prevalence of obesity which is a serious health problem in all over the world especially in industrialized countries. In 2008, more than 1,4 billion adults, 20 and older, were overweight. Of these over 200 million men and nearly 300 million women were obese [1]. Obesity was the highest risk factor for development of a multiple organ dysfunction syndrome and the consequences of obesity include increased risk of cardiovascular disease, pulmonary dysfunction, diabetes, especially colon cancer, fatty liver disease, chronic renal failure and metabolic syndrome[2]. Obesity has been considered a state of chronic low-grade systemic inflammation and chronic oxidative stress. Augmented inflammation in adipose and other tissues promotes the progression of organ damage in obesity [3].

Adipose tissue similar to macrophages secretes a variety of inflammatory mediators such as interleukin-6, leptin and tumor necrosis factor but these mediators induce the production of reactive oxygen species(ROS), generating a process known as oxidative stress [4]. Lipid- rich diets are also capable of generating ROS because they can alter oxygen metabolism. Upon the increase of adipose tissue, the activity of antioxidant enzymes such as superoxide dismutase (SOD), catalase(CAT) and glutathione peroxidase (GPx) was found to be significantly diminished [5]. Finally, high ROS production and the decrease in antioxidant capacity leads to various abnormalities, especially endothelial dysfunction, which is characterized by a reduction in the bioavailability of vasodilators, particularly nitric oxide(NO). Redoxinflammatory processes together with visceral adiposity promote liver dysfunction thus contributing to the onset of dyslipidemia, characterized by hypertriglyceridemia and hyper cholesterolemia and low concentration of high density lipoprotein(HDL) [6].

Plasma concentrations of vitamins and antioxidants are lower in obese individuals than in the non-obese, which is hypothesised to negatively affect the development of inflammation and disease in obesity. Garcia and et al. [7] reported that low concentrations Vit E treated people who were overweight and obese were associated with inflammation and insulin resistance. Therefore, weight loss through nutritional and pharmacological treatment, in addition to supplementation with antioxidant nutrients 
contributes to lower oxidative stress (inflammation, blood lipids) so they been used to combat obesity. For this purpose, different antioxidants such as Vitamin E, C, d-limonene, lycopene and resveratrol has been used so far [8].

Capsaicin (trans-8-methyl- $N$-vannilyl-6-nonemide) is the major pungent principle found in hot red and chilli peppers of the plant genus Capsicum. Studies have reported that this alkaloid component can induce body heat as well as increase energy expenditure, hypolipidemic effect, anti-inflammatory [9] and antioxidant [10] properties. It also decrease in adipose tissue mass have a role to play in weight management. Therefore, in recent years is often used as a supplement to lose weight [11].

Kogure et al. [12] drew attention to the structural similarity of Vit E and CAP and were compare the in vitro antiperoxidative effects of them. The reason we used a combination of antioxidant Vit E and CAP in our study that together they can be more powerful synergistic effect.We examined tissues from high-fat diet mice, a model of low-grade chronic inflammation known to demonstrate enhanced rates of ROS production. Thus, the present study was aimed to determine effects of CAP and Vit E on oxidative stress markers in certain extrahepatic tissue of high-fat diet mice. In addition the anti-obesity effect of these supplement on changes in body weight, plasma triglyceride (TG), total cholesterol (TC), lowdensity lipoprotein (LDL) and (HDL) were also determined.

\section{Materials and Methods}

\subsection{Drugs and Chemicals}

Capsaicin (8-Methyl-N-vanillyl-trans-6-nonenamide), vitamine $\mathbf{E}$ (DL- $\alpha$-Tocopherol acetate) and other chemicals were all purchased from Sigma Chemical Co. (St.Louis, MO, USA). AIN-76 Mineral and vitamine mixture was purchased from MP BIOMEDICALS and all other chemicals used in the experiment were of analytical grade.

\subsection{Animals and Treatment}

All animal handling procedures and the study design were approved by the Medical Research Ethics Committee of Ondokuz Mayis University in Samsun, Turkey (04/ HADYEK, 20th Feb 2012). Beginning of the experiment total of 50 male Swiss albino mice were randomly assigned into two groups, one fed standard diet (NC), $(n=10)$ and the other high fat diet (HF) group; $(n=40)$ which were fed a hight fat diet for 12 weeks to induce obesity. The normal diet contained 5\% fat, 69,2\% carbohydrate, $25,8 \%$ protein and the rests were vitamins, minerals (Mineral mixture for AIN-76A rodent diet; Vitamin mixture for AIN-76A rodent diet), whereas the high-fat diets (TestDiet, USA) comprised $45 \%$ of fat (46,1\% fat from lard, 35,8\% carbohydrate, and 18,1\% protein). After 12 weeks, the HF group was divided into four groups according to whether they received supplements for 4 weeks: the HF group were fed high fat diet only; the HFC group were fed high fat diet with CAP (5 mg/kg, intragasticially); the HFE group were fed high fat diet with Vit E (100 mg/kg, intragasticially) and finally the HFCE group were fed high fat diet with Vit E + CAP.

\subsection{Evaluation of Plasma Biochemical Parameters}

Urea, creatine, creatine kinase MB subunit (CK-MB), $\mathrm{LDH}$ and the all other biochemical parameters TG, TC and HDL in plasma were measured using COBAS Integra 800 automated analyzer by using commercial kits supplied by Roche Diagnostics ( Indianapolis, IN).

\subsection{Sampling Procedures}

At the end of 16 weeks of treatment, animals were killed and tissues (heart, kidney, lung, spleen, thymus and intestine) and fat pads (epididymal, perirenal, and mesenteric) were collected and the weights were measured. Colleced tissues stored at $-80{ }^{\circ} \mathrm{C}$ for further analysis.

\subsection{Measurement of Antioxidant Enzymes and Oxidative Biomarkers}

Catalase activity in the tissues was measured spectrophotometrically at $240 \mathrm{~nm}$ by calculating the rate of degradation of $\mathrm{H}_{2} \mathrm{O}_{2}$ [13]. Superoxide dismutase activity was measured by employing the method of Winterbourn et al. [14]. Glutathione peroxidase activity was measured by the coupled assay method, as described by Paglia and Valentine [15]. The activity of glutathione S-transferase was determined spectrophotometrically at $25^{\circ} \mathrm{C}$. with 1-chloro-2.4-dinitrobenzene as the general substrate [16]. Myeloperoxidase activity in the tissues was determined by the method of Bradley et al [17].

Reduced glutathione level of tissues were determined by the method described by Moron et al. [18]. Lipid peroxidation was estimated by the MDA which is an end product of the peroxidation of polyunsaturated fatty acids [19]. The enzymatic method was used to determine the total NOx level [20]. This method employs the NADHdependent enzyme nitrate reductase for enzymatic reduction of nitrate $\left(\mathrm{NO}_{3}\right)$ to nitrite $\left(\mathrm{NO}_{2}\right)$ prior to the quantification of $\mathrm{NO}_{2}$ using Griess reagent. The total amount of nitrite was calculated from a $\mathrm{NaNO}_{2}(10-100$ $\mu \mathrm{M})$ standard curve.

Protein content was assayed by employing the method of Lowry et al. [21] using bovine serum albumin as the standard.

\subsection{Statistical Analysis}

Data are presented as mean \pm standard deviation (SD). The analysis of data was performed using one-way analysis of variance (ANOVA), followed by Tukey's HSD multiple comparison test. The computer program (SPSS 20) was used for analysis and a p-value of $<0.05$ was regarded as significant.

\section{Results}

\subsection{Body, Organ and Adipose Tissues Weights}

By the end of the 12 weeks the weight of mice which is fed with high fat during 12 weeks was significantly $(\mathrm{P}<0,05)$ higher in the equivalent values for the non-fat control group (Figure 1). The the weight of differences between $12^{\text {th }}$. and $16^{\text {th }}$. week (weight gain) in HF group increased significantly (66,6\%) compared with NC group 
$(\mathrm{P}<0,05)$. Wait gain values were $33,1 \%, 15,1 \%$ and $39,3 \%$ lower for mice in the HFC, HFE and HFCE groups, respectively, than values for the $\operatorname{HF}$ group $(\mathrm{P}<0,05)$. The weight of fat pad increased in the HF compared with NC group $(\mathrm{P}<0,05)$. Weight of fat pad significantly decreased in the HFC and HFCE treated groups compared with HF group $(\mathrm{P}<0,05)$. Organ weights significantly increased in heart, lung, spleen and thymus in all treated groups compared with both NC and HF groups $(\mathrm{P}<0,05)$ (Table 1$)$.

\subsection{Kidney and Heart Injury Markers and Serum Lipid Profile}

Urea, creatine, CK-MB and LDH levels increased HF groups compared with NC group $(\mathrm{P}<0,05)$. Increased level of urea and creatine level did not changed administration of CAP, Vit E or both $(\mathrm{P}>0,05)$. Treatment of CAP and Vit $\mathrm{E}$ individually were completely normalized high fat diet- increased CK-MB and LDH levels but combination of CAP and Vit E treatment did not influence level of these parameters. The serum levels of TG, TC, LDL were significantly increased, whereas HDL was significantly decreased in HF group compared with the NC group $(\mathrm{P}<0,05)$. As for the level of TC and LDL significantly decreased $(\mathrm{P}<0,05)$ and HDL level increased $(\mathrm{P}<0,05)$ in the CAP and Vit E treated groups (Table 2).

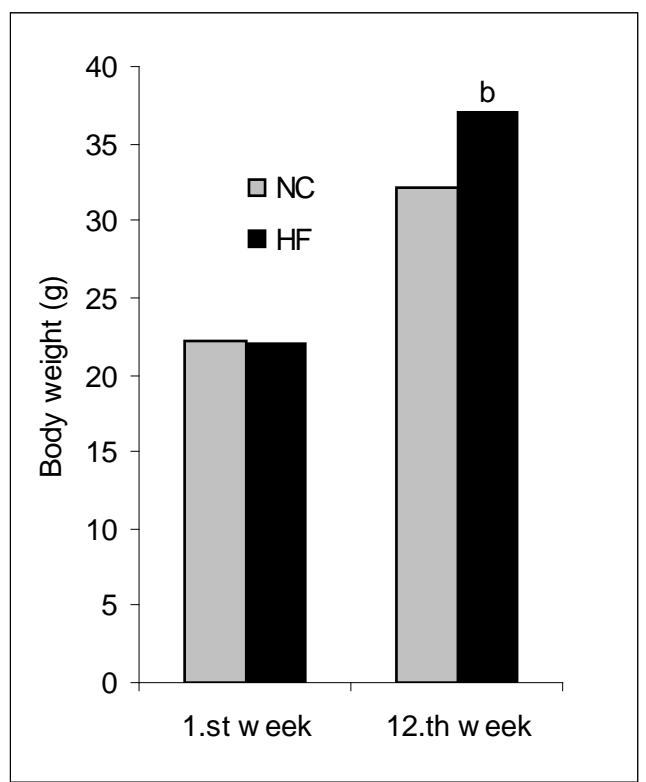

Figure 1. Effects of High-fat Diet on Body Weight Changes in Swiss albino Mice at the End of the 12.th week

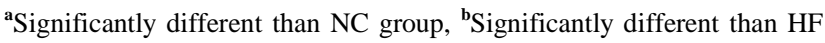
group ANOVA

$(p<0.05)$. NC, fed standard diet $(\mathrm{n}=10)$ and HF, fed high fat diet during 12 weeks to induce obesity; $(\mathrm{n}=40)$.

Table 1. Effects of CAP and Vit E on Body, Organ and Adipose Tissues Weights

\begin{tabular}{|l|l|l|l|l|l|}
\hline Weights(g) & NC & HF & HFC & HFE & HFCE \\
\hline Initial weight (12wk) & $32,21 \pm 1,14$ & $37,00 \pm 1,41^{\mathrm{a}}$ & $37,01 \pm 1,34^{\mathrm{a}}$ & $36,80 \pm 1,31^{\mathrm{a}}$ & $37,21 \pm 1,30^{\mathrm{a}}$ \\
\hline Final weight (16wk) & $35,99 \pm 2,08$ & $43,32 \pm 2,69^{\mathrm{a}}$ & $41,74 \pm 2,11^{\mathrm{a}}$ & $42,57 \pm 3,68^{\mathrm{a}}$ & $41,73 \pm 2,48^{\mathrm{a}}$ \\
\hline Weight gain & $3,78 \pm 1,12$ & $6,30 \pm 1,31^{\mathrm{a}}$ & $4,73 \pm 1,27^{\mathrm{b}}$ & $5,47 \pm 2,42^{\mathrm{a}}$ & $4,52 \pm 1,46^{\mathrm{b}}$ \\
\hline Weight of Fat pad* & $3,20 \pm 0,25$ & $5,65 \pm 0,51^{\mathrm{a}}$ & $4,10 \pm 0,27^{\mathrm{b}}$ & $4,92 \pm 0,36^{\mathrm{a}}$ & $3,97 \pm 0,29^{\mathrm{b}}$ \\
\hline Kidney & $0,48 \pm 0,03$ & $0,56 \pm 0,02^{\mathrm{a}}$ & $0,51 \pm 0,04^{\mathrm{b}}$ & $0,55 \pm 0,02^{\mathrm{a}}$ & $0,51 \pm 0,03^{\mathrm{b}}$ \\
\hline Heart & $0,15 \pm 0,01$ & $0,16 \pm 0,01$ & $0,16 \pm 0,01$ & $0,18 \pm 0,01^{\mathrm{ab}}$ & $0,18 \pm 0,01^{\mathrm{ab}}$ \\
\hline Lung & $0,36 \pm 0,03$ & $0,26 \pm 0,02^{\mathrm{a}}$ & $0,29 \pm 0,02^{\mathrm{a}}$ & $0,32 \pm 0,04^{\mathrm{ab}}$ & $0,30 \pm 0,02^{\mathrm{ab}}$ \\
\hline Intestine & $0,92 \pm 0,07$ & $0,91 \pm 0,05$ & $0,93 \pm 0,06$ & $0,89 \pm 0,09$ & $0,88 \pm 0,05$ \\
\hline Spleen & $0,16 \pm 0,02$ & $0,18 \pm 0,01$ & $0,22 \pm 0,02^{\mathrm{ab}}$ & $0,28 \pm 0,02^{\mathrm{ab}}$ & $0,26 \pm 0,03^{\mathrm{ab}}$ \\
\hline Thymus & $0,06 \pm 0,01$ & $0,05 \pm 0,01$ & $0,07 \pm 0,01^{\mathrm{b}}$ & $0,08 \pm 0,01^{\mathrm{ab}}$ & $0,10 \pm 0,01^{\mathrm{ab}}$ \\
\hline
\end{tabular}

* Fat pad (epididiymal, perirenal and mesenteric adipose tissue)

${ }^{a}$ Significantly different than NC group, bignificantly different than HF group ANOVA

$(p<0.05)$. NC, normal diet; HF, high fat diet; HFC, high fat diet + CAP; HFE, high fat diet + Vit E; HFCE, high fat diet + CAP + Vit E.

\begin{tabular}{|c|c|c|c|c|c|}
\hline & NC & $\mathrm{HF}$ & HFC & HFE & HFCE \\
\hline Urea & $28,61 \pm 2,81$ & $38,40 \pm 2,88^{\mathrm{a}}$ & $36,10 \pm 1,66^{\mathrm{a}}$ & $35,70 \pm 2,26^{\mathrm{a}}$ & $39,80 \pm 2,10^{\mathrm{a}}$ \\
\hline Creatine & $0,91 \pm 0,18$ & $1,42 \pm 0,12^{\mathrm{a}}$ & $1,33 \pm 0,17^{\mathrm{a}}$ & $1,35 \pm 0,09^{\mathrm{a}}$ & $1,37 \pm 0,08^{\mathrm{a}}$ \\
\hline CK-MB & $374,56 \pm 43,38$ & $655,07 \pm 35,35^{\text {a }}$ & $398,85 \pm 55,04^{\mathrm{b}}$ & $574,86 \pm 43,77^{\text {ab }}$ & $637,67 \pm 53,98^{\text {a }}$ \\
\hline LDH & $475,81 \pm 21,38$ & $711,09 \pm 37,19^{a}$ & $513,09 \pm 22,00^{b}$ & $495,38 \pm 27,83^{b}$ & $677,67 \pm 38,06^{a}$ \\
\hline TG & $108,74 \pm 6,40$ & $139,12 \pm 6,24^{\text {a }}$ & $114,41 \pm 4,78^{\mathrm{b}}$ & $116,97 \pm 5,25^{\mathrm{ab}}$ & $119,29 \pm 6,71^{\text {a b }}$ \\
\hline TC & $141,74 \pm 5,45$ & $263,14 \pm 11,26^{a}$ & $195,31 \pm 8,90^{\mathrm{ab}}$ & $188,02 \pm 16,60^{\text {a b }}$ & $191,34 \pm 7,35^{\mathrm{ab}}$ \\
\hline HDL & $33,53 \pm 1,70$ & $18,97 \pm 1,79^{\mathrm{a}}$ & $27,42 \pm 2,00^{\mathrm{ab}}$ & $29,83 \pm 3,25^{\mathrm{ab}}$ & $29,19 \pm 1,64^{\text {a b }}$ \\
\hline LDL & $85,49 \pm 2,90$ & $216,33 \pm 11,79^{a}$ & $145,00 \pm 9,74^{\mathrm{ab}}$ & $134,80 \pm 14,92^{\text {a b }}$ & $138,29 \pm 8,59^{a b}$ \\
\hline
\end{tabular}

${ }^{\mathrm{a}}$ Significantly different than NC group, ${ }^{\mathrm{b}}$ Significantly different than HF group ANOVA $(p<0.05)$.

NC, normal diet; HF, high fat diet; HFC, high fat diet + CAP; HFE, high fat diet + Vit E; HFCE, high fat diet + CAP + Vit E.

CK-MB, creatine kinase-MB; LDH, lactate dehydrogenase; TG, triglyseride; TC, total cholesterol; LDL, low-density lipoprotein and HDL, high density lipoprotein.

\subsection{Antioxidant Enzymes, GSH, MDA and PCs Levels of Extrahepatic Organs}

The activities of both SOD and CAT in almost all tissues of high fat diet mice (heart, lung, intestine and spleen) were significantly lowered than control animals $(\mathrm{P}<0,05)$. Supplementation with CAP or Vit E along with the high fat diet restored the activities of SOD and CAT to varying degrees in all tissues. However, concomitant administration of CAP and vitamin $\mathrm{E}$ has led to more increase in SOD and/or CAT enzyme activities in kidney, heart, intestine and thymus than the control group $(\mathrm{P}<0,05)$. The activities of GPx and GST suppressed almost in all tissues of animals receiving the high fat diet 
as compared to the control mice $(\mathrm{P}<0,05)$. Administering CAP, Vit E or both along with the high fat diet elevated the activities of GPx and GST in all tissues, especially lung and intestine, to near those of the control mice (Table 3).

\begin{tabular}{|c|c|c|c|c|c|c|}
\hline Organs & & NC & $\mathrm{HF}$ & HFC & HFE & HFCE \\
\hline \multirow{4}{*}{ Kidney } & SOD & $8,35 \pm 1,17$ & $7,67 \pm 1,11$ & $8,54 \pm 0,53$ & $7,77 \pm 0,46$ & $9,67 \pm 0,63$ \\
\hline & CAT & $84,00 \pm 6,39$ & $55,77 \pm 17,52^{\mathrm{a}}$ & $46,57 \pm 20,97^{\mathrm{a}}$ & $92,86 \pm 5,95^{b}$ & $92,71 \pm 17,90^{\mathrm{b}}$ \\
\hline & GPx & $0,45 \pm 0,01$ & $0,36 \pm 0,01^{\mathrm{a}}$ & $0,39 \pm 0,02^{\mathrm{a}}$ & $0,37 \pm 0,01^{\text {a }}$ & $0,38 \pm 0,02^{\mathrm{a}}$ \\
\hline & GST & $0,96 \pm 0,10$ & $0,67 \pm 0,07^{\mathrm{a}}$ & $0,74 \pm 0,07$ & $0,92 \pm 0,05^{b}$ & $0,89 \pm 0,06^{b}$ \\
\hline \multirow{4}{*}{ Heart } & SOD & $10,74 \pm 0,60$ & $8,16 \pm 0,88^{\mathrm{a}}$ & $12,19 \pm 1,94^{\mathrm{b}}$ & $9,11 \pm 0,72$ & $10,82 \pm 1,26^{\mathrm{b}}$ \\
\hline & CAT & $45,49 \pm 1,68$ & $30,02 \pm 0,98^{\mathrm{a}}$ & $42,45 \pm 5,06^{\mathrm{b}}$ & $50,87 \pm 9,32^{b}$ & $48,04 \pm 1,43^{b}$ \\
\hline & GPx & $0,08 \pm 0,01$ & $0,06 \pm 0,01^{\text {a }}$ & $0,07 \pm 0,01^{\mathrm{b}}$ & $0,07 \pm 0,01^{\mathrm{b}}$ & $0,07 \pm 0,00^{\mathrm{b}}$ \\
\hline & GST & $0,58 \pm 0,01$ & $0,30 \pm 0,04^{\mathrm{a}}$ & $0,43 \pm 0,05^{\mathrm{ab}}$ & $0,36 \pm 0,03^{\mathrm{a}}$ & $0,39 \pm 0,06^{\mathrm{ab}}$ \\
\hline \multirow{4}{*}{ Lung } & SOD & $11,65 \pm 0,63$ & $8,97 \pm 0,66^{\mathrm{a}}$ & $10,21 \pm 0,79$ & $9,81 \pm 1,29$ & $11,12 \pm 1,40^{\mathrm{ab}}$ \\
\hline & CAT & $71,55 \pm 2,74$ & $47,42 \pm 2,74^{a}$ & $53,87 \pm 5,03^{a}$ & $51,00 \pm 5,38^{\mathrm{a}}$ & $62,61 \pm 2,45^{b}$ \\
\hline & GPx & $0,31 \pm 0,03$ & $0,24 \pm 0,02^{\mathrm{a}}$ & $0,27 \pm 0,02$ & $0,29 \pm 0,01^{\mathrm{b}}$ & $0,33 \pm 0,02^{b}$ \\
\hline & GST & $0,51 \pm 0,06$ & $0,39 \pm 0,03^{a}$ & $0,51 \pm 0,06^{b}$ & $0,57 \pm 0,04^{b}$ & $0,61 \pm 0,08^{b}$ \\
\hline \multirow{4}{*}{ Intestine } & SOD & $2,83 \pm 0,89$ & $1,28 \pm 0,31^{\mathrm{a}}$ & $4,64 \pm 1,39^{b}$ & $4,69 \pm 1,54^{\mathrm{ab}}$ & $4,27 \pm 0,77^{b}$ \\
\hline & CAT & $24,38 \pm 4,00$ & $13,52 \pm 4,97^{\mathrm{a}}$ & $32,75 \pm 2,48^{b}$ & $30,24 \pm 3,87^{b}$ & $37,81 \pm 20,46^{\mathrm{ab}}$ \\
\hline & GPx & $0,25 \pm 0,02$ & $0,18 \pm 0,01^{\mathrm{a}}$ & $0,23 \pm 0,01^{\mathrm{b}}$ & $0,26 \pm 0,02^{b}$ & $0,26 \pm 0,02^{b}$ \\
\hline & GST & $0,43 \pm 0,04$ & $0,28 \pm 0,03^{a}$ & $0,37 \pm 0,06^{b}$ & $0,39 \pm 0,06^{b}$ & $0,38 \pm 0,04^{b}$ \\
\hline \multirow{4}{*}{ Spleen } & SOD & $11,42 \pm 1,96$ & $7,77 \pm 0,49^{\mathrm{a}}$ & $10,62 \pm 1,15^{\mathrm{b}}$ & $7,94 \pm 0,88^{\mathrm{ab}}$ & $11,22 \pm 1,31^{\mathrm{b}}$ \\
\hline & CAT & $41,42 \pm 22,59$ & $25,38 \pm 4,86^{\mathrm{a}}$ & $26,62 \pm 1,42$ & $29,57 \pm 8,20$ & $29,07 \pm 3,56$ \\
\hline & GPx & $0,37 \pm 0,01$ & $0,34 \pm 0,02$ & $0,34 \pm 0,02$ & $0,35 \pm 0,03$ & $0,35 \pm 0,02$ \\
\hline & GST & $0,44 \pm 0,03$ & $0,38 \pm 0,06$ & $0,42 \pm 0,05$ & $0,40 \pm 0,05$ & $0,37 \pm 0,07$ \\
\hline \multirow{4}{*}{ Thymus } & SOD & $13,61 \pm 2,61$ & $9,59 \pm 1,27^{a}$ & $12,58 \pm 1,09^{b}$ & $10,67 \pm 1,75$ & $13,55 \pm 1,09^{b}$ \\
\hline & CAT & $15,00 \pm 4,17$ & $16,95 \pm 2,56$ & $21,62 \pm 0,99$ & $24,27 \pm 4,52^{\text {ab }}$ & $25,17 \pm 6,34^{\mathrm{ab}}$ \\
\hline & GPx & $0,11 \pm 0,01$ & $0,07 \pm 0,01^{\mathrm{a}}$ & $0,10 \pm 0,01^{\mathrm{b}}$ & $0,11 \pm 0,00^{\mathrm{b}}$ & $0,12 \pm 0,01^{\mathrm{b}}$ \\
\hline & GST & $0,35 \pm 0,03$ & $0,28 \pm 0,01^{\text {a }}$ & $0,33 \pm 0,02^{b}$ & $0,33 \pm 0,01^{\mathrm{b}}$ & $0,32 \pm 0,01$ \\
\hline
\end{tabular}

${ }^{\mathrm{a}}$ Significantly different than NC group, ${ }^{\mathrm{b}}$ Significantly different than HF group ANOVA $(p<0.05)$.

NC, normal diet; HF, high fat diet; HFC, high fat diet + CAP; HFE, high fat diet + Vit E; HFCE, high fat diet + CAP + Vit E.

SOD, süperoxide dismutase; CAT, catalase; Gpx, glutathione peroxidase; GST,glutathione-S-Transferase.

The levels of MDA and PCs were significantly increased, whereas GSH level was significantly decreased in the HF group as compared to the NC $(\mathrm{P}<0,05)$. Low glutathione levels in the group of HF were almost completely normalized by treated with CAP, Vit E or both especially in the tissue of spleen and intestine. Similarly, increased MDA and PCs levels by the effects of high fat diet were normalized in all tissues except the kidney in all treated groups (Table 4).

Table 4. Effects of CAP and Vit E on GSH, MDA and PCs Level of High Fat Diet Mice

\begin{tabular}{|c|c|c|c|c|c|c|}
\hline Organs & Parameters $^{2}$ & NC & $\mathrm{HF}$ & HF-C & HF-E & HF-CE \\
\hline \multirow{3}{*}{ Kidney } & GSH & $11,20 \pm 0,71$ & $8,20 \pm 0,98^{\mathrm{a}}$ & $8,08 \pm 0,76^{a}$ & $8,33 \pm 0,67^{\mathrm{a}}$ & $7,94 \pm 0,43^{\text {a }}$ \\
\hline & MDA & $148,10 \pm 9,94$ & $198,85 \pm 10,83^{\mathrm{a}}$ & $169,19 \pm 13,79^{a}$ & $158,65 \pm 22,17^{\mathrm{ab}}$ & $175,58 \pm 17,85^{\mathrm{a}}$ \\
\hline & PCs & $0,09 \pm 0,01$ & $0,13 \pm 0,01^{\mathrm{a}}$ & $0,11 \pm 0,01^{\mathrm{a}}$ & $0,12 \pm 0,01^{\mathrm{a}}$ & $0,10 \pm 0,01^{\mathrm{b}}$ \\
\hline \multirow{3}{*}{ Heart } & GSH & $14,21 \pm 1,13$ & $9,77 \pm 0,42^{\text {a }}$ & $12,35 \pm 0,99^{\text {a }}$ & $12,70 \pm 0,83^{\mathrm{ab}}$ & $12,35 \pm 0,99^{\text {a b }}$ \\
\hline & MDA & $251,36 \pm 35,87$ & $402,44 \pm 28,10^{\text {a }}$ & $316,73 \pm 34,27^{b}$ & $300,19 \pm 41,43^{b}$ & $306,89 \pm 52,09^{b}$ \\
\hline & PCs & $0,16 \pm 0,01$ & $0,24 \pm 0,01^{\text {a }}$ & $0,19 \pm 0,02^{b}$ & $0,17 \pm 0,02^{b}$ & $0,21 \pm 0,01^{\text {ab }}$ \\
\hline \multirow{3}{*}{ Lung } & GSH & $11,21 \pm 1,00$ & $7,18 \pm 1,01^{\text {a }}$ & $9,49 \pm 0,65^{\text {ab }}$ & $9,11 \pm 0,63^{\mathrm{ab}}$ & $9,22 \pm 0,61^{\text {ab }}$ \\
\hline & MDA & $81,19 \pm 6,25$ & $113,44 \pm 14,03^{\mathrm{a}}$ & $91,00 \pm 7,29^{b}$ & $95,58 \pm 8,33^{b}$ & $78,00 \pm 5,30^{b}$ \\
\hline & PCs & $0,12 \pm 0,01$ & $0,18 \pm 0,02^{\mathrm{a}}$ & $0,14 \pm 0,01^{\mathrm{b}}$ & $0,12 \pm 0,01^{\mathrm{b}}$ & $0,10 \pm 0,01^{\mathrm{b}}$ \\
\hline \multirow{3}{*}{ Intestine } & GSH & $10,47 \pm 0,85$ & $6,70 \pm 0,53^{\mathrm{a}}$ & $10,01 \pm 0,61^{b}$ & $11,37 \pm 0,88^{b}$ & $11,71 \pm 0,91^{\mathrm{b}}$ \\
\hline & MDA & $43,13 \pm 3,28$ & $60,34 \pm 4,86^{\mathrm{a}}$ & $45,71 \pm 3,63^{b}$ & $47,82 \pm 4,81^{\mathrm{b}}$ & $46,14 \pm 3,49^{b}$ \\
\hline & PCs & $0,04 \pm 0,01$ & $0,06 \pm 0,00^{\text {a }}$ & $0,05 \pm 0,01^{\mathrm{b}}$ & $0,05 \pm 0,01^{b}$ & $0,05 \pm 0,01^{b}$ \\
\hline \multirow{3}{*}{ Spleen } & GSH & $7,74 \pm 0,62$ & $5,77 \pm 0,46^{\text {a }}$ & $7,18 \pm 0,30^{\mathrm{b}}$ & $7,63 \pm 0,32^{b}$ & $8,20 \pm 0,92^{b}$ \\
\hline & MDA & $166,01 \pm 17,23$ & $237,63 \pm 11,14^{\mathrm{a}}$ & $190,50 \pm 13,85^{b}$ & $182,75 \pm 19,58^{b}$ & $189,22 \pm 20,67^{b}$ \\
\hline & PCs & $0,14 \pm 0,01$ & $0,19 \pm 0,01^{\text {a }}$ & $0,14 \pm 0,01^{\mathrm{b}}$ & $0,11 \pm 0,01^{\mathrm{ab}}$ & $0,12 \pm 0,02^{b}$ \\
\hline \multirow{3}{*}{ Thymus } & GSH & $5,29 \pm 0,59$ & $3,18 \pm 0,24^{\mathrm{a}}$ & $3,82 \pm 0,16^{\text {ab }}$ & $3,97 \pm 0,13^{\text {ab }}$ & $4,54 \pm 0,19^{\mathrm{ab}}$ \\
\hline & MDA & $176,80 \pm 18,57$ & $241,69 \pm 19,04^{\mathrm{a}}$ & $203,75 \pm 34,30$ & $194,75 \pm 23,5^{b}$ & $182,77 \pm 9,19^{\mathrm{b}}$ \\
\hline & PCs & $0,10 \pm 0,01$ & $0,19 \pm 0,02^{\text {a }}$ & $0,14 \pm 0,01^{\text {ab }}$ & $0,12 \pm 0,01^{\mathrm{b}}$ & $0,10 \pm 0,01^{\mathrm{b}}$ \\
\hline
\end{tabular}

${ }^{\mathrm{a}}$ Significantly different than NC group, ${ }^{\mathrm{b}}$ Significantly different than HF group ANOVA

$(p<0.05)$.

NC, normal diet; HF, high fat diet; HFC, high fat diet + CAP; HFE, high fat diet + Vit E; HFCE, high fat diet + CAP + Vit E.

GSH, reduced glutathione; MDA, malondialdehyde; PCs, protein carbonyl. 
MPO activity was increased in HF group when compared with NC group in all tissues. High MPO activities in the group of $\mathrm{HF}$ in the tissue of lung and kidney were almost completely normalized by treated with CAP and Vit E separately groups. When administered separately CAP or Vit E along with the high fat diet restored the activities MPO varying degrees in all tissues $(\mathrm{P}<0,05)$. However, concomitant administration of CAP and vitamin $\mathrm{E}$ did not improved high fat diet induced inreased MPO activities in kidney, lung, intestine and spleen $(\mathrm{P}>0,05)$ (Figure 2). NO concentration is also increased as the MPO activity in HF group ( $p>0.05$ ) in all tissues when compared with NC group Vitamine E treatment increased NO level almost in all tissues compared with NC groups. However, CAP ve Vit E treatment with together significantly decreased NO level when compared with HF and NC groups $(\mathrm{P}<0,05)$ (Figure 3$)$.

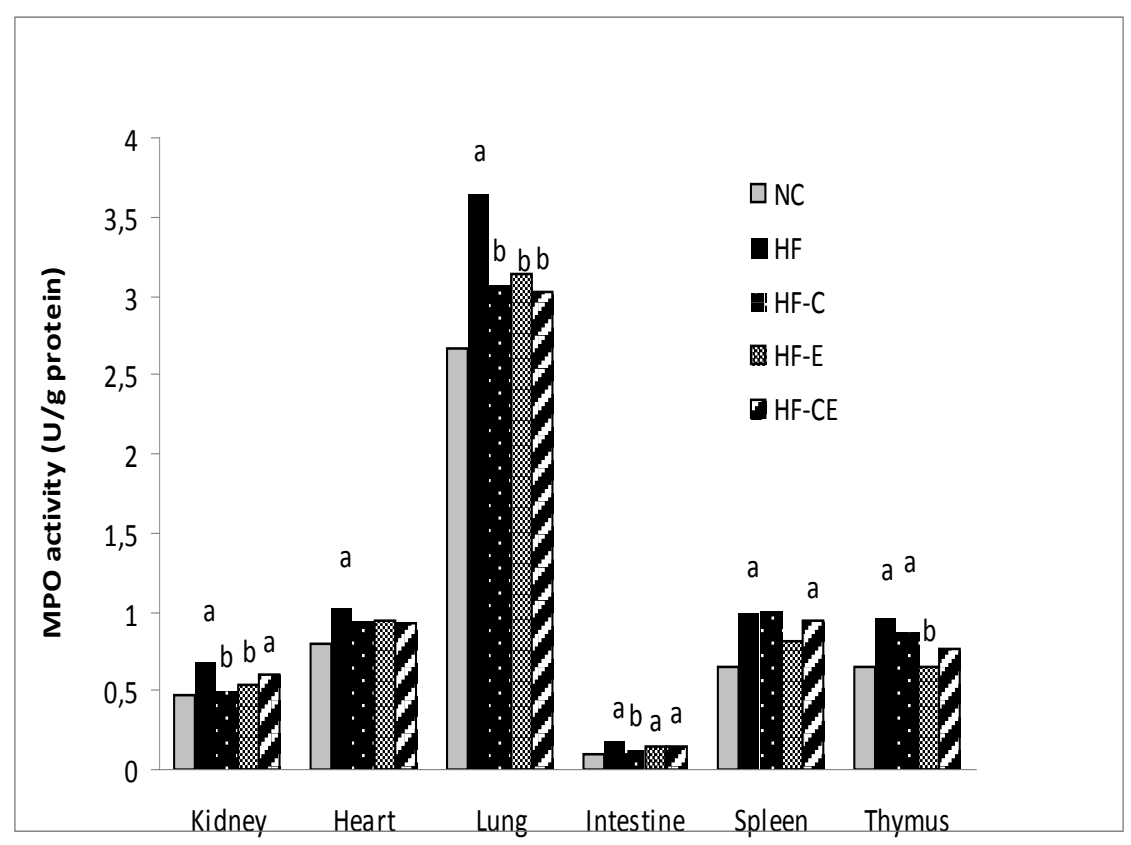

Figure 2. Effects of CAP and Vit E on Myeloperoxidase Activities in the Extrahepatic Organs

${ }^{\mathrm{a}}$ Significantly different than NC group, ${ }^{\mathrm{b}}$ Significantly different than HF group ANOVA

$(p<0.05)$. NC, normal diet; HF, high fat diet; HFC, high fat diet + CAP; HFE, high fat diet + Vit E; HFCE, high fat diet + CAP + Vit E.

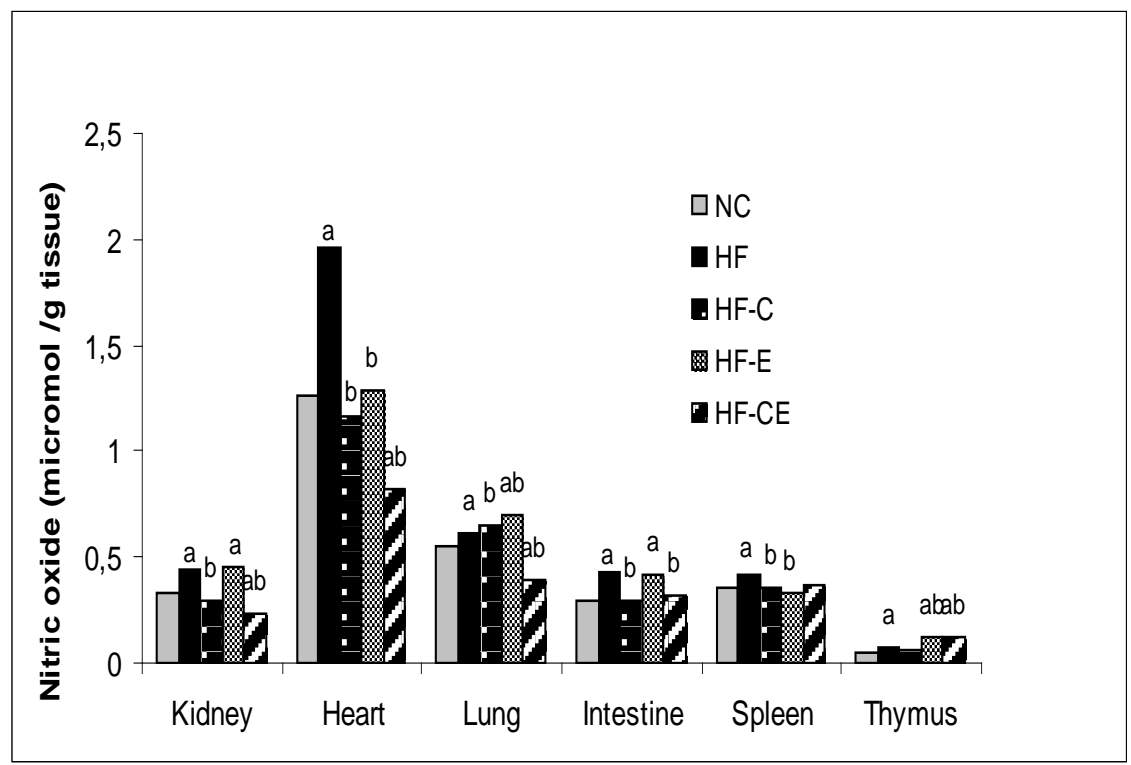

Figure 3. Effects of CAP and Vit E on Nitric Oxide Level in the Different Extrahepatic Organs

${ }^{a}$ Significantly different than NC group, ${ }^{\mathrm{b}}$ Significantly different than HF group ANOVA

$(p<0.05)$.

NC, normal diet; HF, high fat diet; HFC, high fat diet + CAP; HFE, high fat diet + Vit E; HFCE, high fat diet + CAP + Vit E.

\section{Discussion}

This present study, we found that obesity was induced in mice by feeding a high-fat diet containing $40 \%$ beef tallow and 15,62\% increase were seen in body weight in HF group compared to NC group at the end of the 12 th. week (Figure 1). We also found that feeding high fat diet together with CAP or Vit E together CAP for 4 weeks suppressed the increases in body, some organs and 
adipose tissue weights induced by a HF (Table 1). Although effect of vitamin E supplementation on body mass index is not conclusive, Lira et al. [22] demonstrated that high fat feding mice additional four weeks with the same diet supplemented with alpha-tocopherol $(0,9 \mathrm{~g} / \mathrm{kg}$ of diet) body waight gain decresed aproxtimally 50\%. Increased fat pad weight by the effects of high fat feeding also decrese by treatment with CAP or CAP+Vit E treatment. CAP is known to suppress body fat accumulation and reduce body weight by enhancing of energy expenditure in both rodent and humans [23]. Rats were fed high fat diet together with different concentrations of CAP for 10 days decreased were seen epididymal and perirenal adipose tissues [11]. Similar effect were observed on a human study; capsinoids taken orally $(6 \mathrm{mg} / \mathrm{d})$ for 12 -wk decresed abdominal adiposite tissue compared with the placebo group [24]. Also, data from obtained Medical databases demonstrated that capsinoids may have potential to form the basis of weight loss aids [25]. A number of different mechanisms could be responsible for the anti-obesity effects of CAP. Capsaicin consumption was reported to increase energy expenditure and lipid oxidation. The effects of CAP on energy and lipid metabolism are attributed to an increase in sympathetic nervous system activity increased blood flow and secretion in the gastrointestinal tract neurons resulting into increased noradrenaline levels [26]. The other mechanisms that CAP increased peroxisome proliferator activated receptor (PPAR) alpha and TRPV-1 expression in adipose tissue and liver [27]. Leung et al. [28] demonstrated that CAP caused an increase in intestinal blood flow but decrease in visceral adipose blood flow; this may be attributed to the reduced viceral pad capacity of the CAP. We observed that high fat diet together with CAP (5 mg/kg, 30 days) or CAP+ Vit E treatment increased spleen and thymus weights compared with high fat diet. On the other hand, spleen weights significantly decreased in CAP (50 mg/kg, single subcutanous dose) treatment after 4 weeks [29].

In our study, the levels of kidney (urea and creatinine) and heart (CK-MB and LDH) injury markers were increased in HF-fed mice and restored to normal in CAP and Vit E treated alone. However, when given together not improvement of these parameters, even more increases were observed.

Obesity can be considered as an abnormal state of blood lipid metabolism and hyperlipidemia. In this study, high fat feeding resulted in dyslipidemic changes as hypercholesterolemia and hypertriglyceridemia and low level of HDL cholesterol as compared with control; a finding in accordance with that of Noeman and Hamooda [5] and Oh et al [30]. Although CAP and vitamin E treatment, combined or alone, reduced of high-fat diet induced hyperlipidemia (decresed in TG, LDL and TC and increased HDL) but did not completely improvements. Fruebis et al. [31] raported that vitamin E was shown to have hypolipidemic effects. On the other hand, Hasty et al. [32] observed that no effects of Vit E (2000 IU/kg) on hiperlipidemia on obese mouse model. Capsaicin treatment reduced serum total cholesterol and lipid peroxide level in dietary high-fat-fed rats [33]. Regular consumption of chilli for 4 weeks has been found to increase the resistance of serum lipoproteins to oxidation in adult men and women [34]. These reports support the antioxidant property of capsinoids and their potential clinical value on the prevention of cardiovascular diseases, such as atherosclerosis and coronary heart diseases.

We observed significant reduction in antioxidant enzymes such as SOD, CAT, GPx and GST activity and glutathione level in almost all tissue of high fat feding mice compared with non-fat animals. On the other hand non-enzymatic oxidative stress parameters lipid peroxidation markers MDA and protein oxidation markers PCs level increased in these tissues. GSH is important not only as an antioxidant, but also as a cofactor for the enzymes GST and GPx, which are involved in the antioxidant response. Several studies has been shown that high fat diet induced obesity decrease antioxidant capacity in different organs such as increased indices of lipid and protein oxidation in hearts of rodent [35]. Decreases were observed in glutathione peroxidases level in serum, kidney and adipose tissue of rats [36]. On the other hand, increases were observed in different oxidative stress parameters in liver, kidney and heart of rats [5] and mice [37]. Low glutathione levels in the group of $\mathrm{HF}$ in the tissue of lung, spleen, thymus and heart were almost completely normalized by treated with CAP, Vit E or both groups. Similarly, increased MDA and PCs levels by the effects of high fat diet were normalized in all tissues except the kidney in all treated groups (HF-C, HF-E, HF$\mathrm{CE})$. As our study CAP project different tissue from oxidative damage because its ability antioxidant capacity $[10,12,33]$. Thus, supplementation with antioxidants such as vitamins $\mathrm{E}, \mathrm{A}$, and $\mathrm{C}$, flavonoids and capsaicinoids may act as a regulator of obesity and would reduce the obesity related oxidative stress [38].

Results from our study clearly show that increased inflammation in high fat feding mice, as evidenced by a significant increase in MPO activity and NO level in HF group. A number of clinical and animal studies have shown that oxidative stress and inflammation appear to be closely interlinked in obesity because adipose tissue identified as a source of proinflammatory cytokines, including TNF- $\alpha$, IL-1, and IL-6. These cytokines are potent stimulators for the production of reactive oxygen and nitrogen by macrophages therefore, a rise in the concentration of cytokines could be responsible for increased oxidative stress [4]. Patel et al. [38] showed that a diet high in fat and carbohydrates induces a significant increase in oxidative stress and inflammation in persons with obesity. In our study, increased MPO activities in kidney, heart, lung, intestine, spleen and thymus can be explained by neutrophil infiltration to the these tissues. The infiltration of neutrophil to organ tissues caused MPO-derived oxidants damage and initiates tissue inflammation. Myeloperoxidase activities improved almost in all tissues of high fat diet mice by the treatment of CAP, Vit E or combined of them. Kang et al. [39] demonstrated that capsaicin has inhibitory effect on adipose tissue inflammatory responses involving reduced inflammatory adipocytokine release from adipose tissue in diet-induced obese mice.

Nitric oxide is a physiological regulator of diverse functions in several tissues including cardiovascular, neuromuscular, neurological, genitourinary, gastrointestinal and renal. High fat diet induced NO activities were observed in different tissues such as small intestine in rats [40] and liver in mice [41]. Martins et al. [42] also 
demonstrated that the group fed with a diet rich in lard, a saturated high fat diet, presented an inhibition of the Larginine-NO pathway in red blood cells in mice. Similarly, in our study high fat diets affected NO production in all organ tissues. Inducible nitric oxide synthase (iNOS) mRNA and protein activity have also been found to be induced in rats on a high-fat diet [43]. In parallel to our findings, alpha- tocopherol induced nitric oxide synthase activity in blood vessels [44] and in penile tissue [45] of rats were also demonstrated. Interestingly, Vit E caused a further increase NO levels which is already increased by the effect of high-fat diet in all tissue except heart. On the other hand, when given CAP and Vit E together NO levels decreased significantly compared with high fat diet group, even at a level significantly less than the control group was found.

\section{Conclusion}

In conclucions, thus, taking into consideration our results and other reports, we can assume that high fat diet induced obesity and hyperlipidemia have synergistic effects on promoting systemic oxidative stress and organ toxicity, as evidenced by increased lipid peroxidation, protein carbonyls and decreased glutathione and antioxidant enzymes. Capsaicin and Vit E ameliorate these toxicity which might be explained partially via diminishing the generation of free radicals and hyperlipidemia.

It is assumed that combination of some supplements might synergistically increase or decrease the efficacy or toxicity of supplements. Based on this in our study; CAP and Vit E given together has been more effective on both decreasing weight gain, fat pad and inflammation (decrease NO level especially kidney, heart, lung and intestine) than the groups these supplement given separately. On the other hand, combined supplementation of CAP and Vit E showed not better effect on high fat diet induced oxidative stress and hyperlipidemia as compared to CAP or Vit E treatment alone. Moreover, combined supplementation of these substance not restored the organ damage markers (such as urea, creatine, CK-MB and LDH) and even caused to continue organ damage as compared to CAP or Vit E treatment alone. Further in vivo studies are needed which will be assessed synergistic effect of Vitamin E and CAP.

\section{Acknowledgements}

This study was supported by FBM-BAP-12-004 Project funded by the Amasya University (Republic of Turkey) in 2012.

\section{Statement of Competing Interests}

None.

\section{References}

[1] Ruth, S.M., Chan and Jean, Woo., Prevention of Overweight and Obesity: How Effective is the Current Public Health Approach.
International Journal of Environmental Research and Public Health, 7(3), 765-783, 2010.

[2] Andruszkow, H., Veh, J., Mommsen, P., Zeckey, C., Hildebrand, F., Frink, M., Impact of the body mass on complications and outcome in multiple trauma patients: what does the weight weigh? Mediators of Inflammation, May 2013. [Online] Available: http://www.hindawi.com/journals/mi/2013/345702/.

[3] Ciesla, D.J., Moore, E.E., Johnson, J.L., Burch, J.M., Cothren, C.C., Sauaia, A., Obesity increases risk of organ failure after severe trauma. Journal of the American College of Surgeons, 203, 39-45, 2006.

[4] Capel, I and Dorrell, A., Abnormal antioxidant defense in some tissues of congenitally obese mice, Biochemistry, 219, 41-49, 1984.

[5] Noeman, S.A., Hamooda, H.E., Biochemical study of oxidative stress markers in the liver, kidney and heart of high fat diet induced obesity in rats. Diabetology \& Metabolic Syndrome, 3, 117, 2011.

[6] Bryan, S., Baregzay, B., Spicer, D., Singal, P.K., Khaper, N., Redox-inflammatory synergy in the metabolic syndrome. Canadian Journal of Physiology and Pharmacology, 91, 22-30, 2013.

[7] García, O.P., Ronquillo, D., del Carmen Caamaño, M., Martínez, G., Camacho, M., López, V., Rosado, J.L., Zinc, iron and vitamins A, C and e are associated with obesity, inflammation, lipid profile and insulin resistance in Mexican school-aged children. Nutrients, 5(12), 5012-30, 2013.

[8] Waye, M.M., New insights into how adenovirus might lead to obesity: An oxidative stress theory. Free Radical Research, 45(8), 880-7, 2011.

[9] Choi, S.E., Kim, T.H., Yi, S.A., Hwang, Y.C., Hwang, W.S., Choe, S.J., Han, S.J., Kim, H.J., Kim, D.J., Kang, Y., Lee, K.W., Capsaicin attenuates palmitate-induced expression of macrophage inflammatory protein 1 and interleukin 8 by increasing palmitate oxidation and reducing c-Jun activation in THP-1 (human acute monocytic leukemia cell) cells. Nutrition Research, 31(6), 468-78, 2011.

[10] Henning, S.M., Zhang, Y., Seeram, N.P., Lee, R.P., Wang, P., Bowerman, S., Heber, D., Antioxidant capacity and phytochemical content of herbs and spices in dry, fresh and blended herb paste form. International Journal of Food Sciences and Nutrition, 62(3), 219-25 2011.

[11] Kawada, T., Hagihara, K., Iwai, K., Effects of capsaicin on lipid metabolism in rats fed a high fat diet. Journal of Nutrition, 116, 72-1278, 1986.

[12] Kogure, K., Goto, S., Nishimura, M., Yasumoto, M., Abe, K., Ohiwa, C., Sassa, H., Kusumi, T., Terada, H., Mechanism of potent antiperoxidative effect of capsaicin. Biochimica et Biophysica Acta, 1573(1), 84-92, 2002.

[13] Aebi, H., Catalase in vitro. Methods of Enzymology, 105, 121-126, 1984.

[14] Winterbourn, C.C., Hawkins, R.E., Brian, M., Carrell, R.W., The estimation of red cell superoxide dismutase activity. The Journal of Laboratory and Clinical Medicine, 85, 337-341, 1975.

[15] Paglia, D.E and Valentine, W.N., Studies on the quantitative and qualitative characterization of erytrocyte glutathione peroxidase. The Journal of Laboratory and Clinical Medicine, 70, 158-169, 1967.

[16] Habig, W.H., Pabst, M.J., Jakoby, W.B., Glutathione Stransferases. The first enzymatic step in mercapturic acid formation. Journal of Biological Chemistry, 249, 7130-7139, 1974

[17] Bradley, P.P., Priebat, D.A., Christensen, R.D., Rothstein, G., Measurement of cutaneous inflammation, estimation of neutrophil content with an enzyme marker. Journal of Investigative Dermatology, 78, 206-209, 1982.

[18] Moron, M.S., Depierre, J.W., Mannervik, B., Levels of GSH, GR and GST activities in rat lung and liver. Biochimica et Biophysica Acta, 582, 67-78, 1979.

[19] Esterbauer, H., Chessman, K.H., Determination of aldeydic lipid peroxidation products: malonaldeyde and 4-hydroxynonenal. Methods in Enzymology, 186, 407-421, 1990.

[20] Doganay, S., Evereklioglu, C., Er, H., Türközk, Y., Sevinç, A. Mehmet, N., Savli, H., Comparison of serum NO, TNF-alpha, IL1beta, sIL-2R, IL-6 and IL-8 levels with grades of retinopathy in patients with diabetes mellitus. Eye, 16, 163-170, 2002.

[21] Lowry, O.H., Rosebrough, N.J., Farr, A.L., Randall, R.J., Protein measurement with the folin phenol reagent. Journal of Biological Chemistry, 193, 265-275, 1951. 
[22] Lira, F.S., Rosa, J.C., Cunha, C.A., Ribeiro, E.B., do Nascimento, C.O., Oyama, L.M., Mota, J.F., Supplementing alpha-tocopherol (vitamin E) and vitamin D3 in high fat diet decrease IL-6 production in murine epididymal adipose tissue and 3T3-L1 adipocytes following LPS stimulation. Lipids in Health and Disease, Feb 2011. (Online) Available: http://www.ncbi.nlm.nih.gov/pubmed/21352586.

[23] Haramizu, S., Kawabata, F., Ohnuki, K., Inoue, N., Watanabe, T., Yazawa, S., Fushiki, T., Capsiate, a non-pungent capsaicin analog, reduces body fat without weight rebound like swimming exercise in mice. Biomedical Research, 32(4), 279-84, 2011.

[24] Snitker, S., Fujishima, Y., Shen, H., Ott, S., Pi-Sunyer, X., Furuhata, Y., Sato, H., Takahashi, M., Effects of novel capsinoid treatment on fatness and energy metabolism in humans: possible pharmacogenetic implications. American Journal of Clinical Nutrition, 89(1), 45-50, 2009.

[25] Whiting, S., Derbyshire, E., Tiwari, B.K., Capsaicinoids and capsinoids. A potential role for weight management? A systematic review of the evidence. Appetite, 59(2), 341-8, 2012.

[26] Belza, A., Frandsen, E., Kondrup, J., Body fat loss achieved by stimulation of thermogenesis by a combination of bioactive food ingredients: a placebo-controlled, double-blind 8-week intervention in obese subjects. International Journal of Obesity, 31(1), 121-30, 2007.

[27] Kang, J.H., Goto, T., Han, I.S., Kawada, T., Kim, Y.M., Yu, R., Dietary capsaicin reduces obesity-induced insulin resistance and hepatic steatosis in obese mice fed a high-fat diet. Obesity, 18(4), 780-7, 2010

[28] Leung, F.W., Golub, M., Tuck, M., Yip, I., Leung, J.W., Go, V.L.,) Stimulation of intestinal mucosal afferent nerves increases superior mesenteric artery and decreases mesenteric adipose tissue blood flow. Digestive Diseases and Sciences, 46(6), 1217-22, 2001.

[29] Sandberg, G., Ljungdahl, A.,Mitogenic responses of splenic B and $\mathrm{T}$ lymphocytes in neonatally capsaicin-treated mice. International Archives of Allergy and Applied Immunology, 81(4), 343-7, 1986.

[30] Oh, J.S., Lee, S.R., Hwang, K.T., Ji, G.E., The anti-obesity effects of the dietary combination of fermented red ginseng with levan in high fat diet mouse model. Phytotherapy Research, 28(4), 617-22, 2014.

[31] Fruebis, J., Carew, R.E., Palinski, W., Effect of vitamin E on atherogenesis in LDL receptor-deficient rabbits. Atherosclerosis, 117, 617-26, 1995.

[32] Hasty, A.H., Gruen, M.L., Terry, E.S., Surmi, B.K., Atkinson, R.D., Gao, L., Morrow, J.D., Effects of vitamin E on oxidative stress and atherosclerosis in an obese hyperlipidemic mouse model. Journal of Nutritional Biochemistry, 18(2), 127-33, 2007.

[33] Manjunatha, H., Srinivasan, K., Hypolipidemic and antioxidant effects of curcumin and capsaicin in high-fat-fed rats. Canadian Journal of Physiology and Pharmacology, 85, 588-596, 2007.
[34] Ahuja, K.D., Ball, M.J., Effects of daily ingestion of chilli on serum lipoprotein oxidation in adult men and women. British Journal of Nutrition, 96, 239-242, 2006.

[35] Wang, S., Kaufman, R.J., The impact of the unfolded protein response on human disease. Journal of Cell Biology, 197, 857-867, 2012.

[36] Asayama, K., Nakane, T., Dobashi, K., Kodera, K., Hayashibe, H., Uchida, N., Nakazawa, S., Effect of obesity and troglitazone on expression of two glutathione peroxidases: cellular and extracellular types in serum, kidney and adipose tissue. Free Radical Research, 34(4), 337-47, 2001.

[37] Muthulakshmi, S., Saravanan, R., (2013) Protective effects of azelaic acid against high-fat diet-induced oxidative stress in liver, kidney and heart of C57BL/6J mice. Molecular and Cellular Biochemistry, 377(1-2), 23-33, 2013.

[38] Patel, C., Ghanim, H., Ravishankar, S., Sia, C.L., Viswanathan, P., Mohanty, P., Dandona, P., Prolonged reactive oxygen species generation and nuclear factor-kappaB activation after a high-fat, high-carbohydrate meal in the obese. Journal of Clinical Endocrinology and Metabolism, 92(11), 4476-9, 2007.

[39] Kang, J.H, Kim, C.S., Han, I.S., Kawada, T., Yu, R., Capsaicin, a spicy component of hot peppers, modulates adipokine gene expression and protein release from obese-mouse adipose tissues and isolated adipocytes, and suppresses the inflammatory responses of adipose tissue macrophages. FEBS Letters, 581, 4389-4396, 2007.

[40] Ou, Y., Liu, R., Wei, N., Li, X., Qiang, O., Huang, W., Tang, C., Effects of octreotide on nitric oxide synthase expression in the small intestine of high fat diet-induced obese rats. Obesity Research \& Clinical Practice, 6(4),263-346, 2012.

[41] Ha, S.K., Chae, C., Inducible nitric oxide distribution in the fatty liver of a mouse with high fat diet-induced obesity. Experimental Animals, 59(5), 595-604,2010.

[42] Martins, M.A., Catta-Preta, M., Mandarim-de-Lacerda, C.A., Aguila, M.B., Brunini, T.C., Mendes-Ribeiro, A.C., High fat diets modulate nitric oxide biosynthesis and antioxidant defence in red blood cells from C57BL/6 mice. Archives of Biochemistry and Biophysics, 499(1-2), 56-61,2010.

[43] Kim, J.W., Kang, K.W., Oh, G.T., Song, J., Kim, N.D., Pak, Y.K., Induction of hepatic inducible nitric oxide synthase by cholesterol in vivo and in vitro. Experimental \& Molecular Medicine, 34, 137144, 2002.

[44] Newaz, M.A., Nawal, N.N., Rohaizan, C.H., Muslim, N., Gapor, A., alpha-Tocopherol increased nitric oxide synthase activity in blood vessels of spontaneously hypertensive rats. American Journal of Hypertension, 12(8), 839-44, 1999.

[45] Tronchini, E.A., de Miranda Neto, M.H., Zanoni, J.N., Vitamin E ( $\alpha$-tocopherol) supplementation enhances nitric oxide production in penile tissue of diabetic rats. BJU International, 106(11), 178893, 2010. 